\title{
M-CSF Receptor Antagonists Inhibit the Initiation and Progression of Hepatocellular Carcinoma in Mice
}

\author{
YOSHIHIRO AKAZAWA, HIROSHI KONO, MICHIO HARA, SHINJI FURUYA, YUUKI NAKATA, \\ HIROYUKI WAKANA, HISATAKA FUKUSHIMA, CHAO SUN, HIDEKI FUJII and DAISUKE ICHIKAWA
}

First Department of Surgery, Faculty of Medicine, University of Yamanashi, Yamanashi, Japan

\begin{abstract}
Background/Aim: The aim of this study was to investigate the effects of the macrophage colony-stimulating factor (M-CSF) receptor antagonist on hepatic carcinogenesis in mice. Materials and Methods: Mice were injected with diethylnitrosamine (DEN) and treated with M-CSF receptor antagonist $G W 2580(G W)$ or a saline vehicle just after (early treated group) or 2 weeks after (late treated group) DEN injection. Animals were sacrificed after 28 weeks and incidence of tumor was assessed. Isolated Kupffer cells were co-cultured with M-CSF in the presence or absence of GW, and the concentration of VEGF was measured. Results: The incidence of tumors was significantly blunted both in the early-and the late-treated groups. In addition, angiogenesis within the tumor was also suppressed in both groups. The concentration of $V E G F$ increased in Kupffer cells treated with M-CSF compared to those cultured without M-CSF. This increase was blunted by GW. Conclusion: M-CSF and its receptor could be novel molecular targets for hepatocellular carcinoma.
\end{abstract}

Macrophage colony-stimulating factor (M-CSF), which is a cytokine inducing differentiation and activation of monocytes and macrophages, has a strong migratory activity on macrophages, vascular endothelial cells and fibroblasts (1-4). Recently, it was reported that expression of M-CSF in nontumor liver tissues was associated with disease recurrence, and poor survival after hepatectomy in human hepatocellular carcinoma (HCC), indicating the importance of the peritumoral tissue environment in the intrahepatic recurrence of $\operatorname{HCC}(5,6)$.

Correspondence to: Hiroshi Kono, First Department of Surgery, Faculty of Medicine, University of Yamanashi, 1110 Shimokato, Chuo, Yamanashi 409-3898, Japan. Tel: +81 0552737390, Fax: +81 0552736751,e-mail: hkouno@yamanashi.ac.jp

Key Words: Macrophage colony-stimulating factor, macrophage colony-stimulating factor receptor antagonist, hepatic macrophage, diethylnitrosamine, hepatocellular carcinoma.
There are two subtypes of macrophages, M1-type and M2type. M1-type macrophage is an inflammation-inducing macrophage stimulated with a Th1 type cytokine. In contrast, M2-type macrophages are stimulated by Th2 type cytokines and are thought to be strongly related to tumor growth (6). Many of the tumor-associated macrophages are thought to be M2-type macrophages expressing CD163, CD204 and/or CD206. M2-type macrophage secrete growth factors which are essential for tumor growth and invasion $(6,7)$. Indeed, MCSF induces vascular endothelial growth factor (VEGF) production and angiogenic activity in human monocytes (6). Furthermore, inhibition of M-CSF decreased significantly infiltration of macrophages, resulting in a significant delay of tumor progression. In contrast, overexpression of M-CSF or supplementation with recombinant M-CSF resulted in enhancement in the recruitment of macrophages and correlated with accelerated tumor growth, progression, and angiogenesis $(6,8-10)$. Previously, it was reported from this laboratory that occurrence and progression of chemicallyinduced hepatocellular carcinoma (HCC) were significantly lower in M-CSF-deficient mice than in wild-type mice (11, 12). Furthermore, it was also reported that recurrence of HCC after curative resection was much faster in patients with high expression of M-CSF in non-tumor liver tissue than patients with low expression of M-SCF $(6,13)$. In that study, intrahepatic expression of M-CSF was associated with M2type macrophages and angiogenesis $(6,13)$. Thus, M-CSF is involved in induction and progression of HCC by inducing angiogenesis via M2-type macrophages and could be a novel molecular target for treatment of $\operatorname{HCC}(4,6)$. Therefore, the specific purpose of this study was to investigate effects of MCSF receptor antagonist on HCC in mice.

\section{Materials and Methods}

Animals. Male C3H/HeN (2 weeks old, obtained from Slc, Shizuoka, Japan) mice were housed in a clean, temperaturecontrolled environment with a $12 \mathrm{~h}$ light-dark cycle and were given free access to regular laboratory water and chow diet for several days. All animals received humane care, and the study protocols 
were approved by the Committee of Laboratory Animals at the University of Yamanashi according to institutional guidelines.

$M$-CSF receptor antagonist GW2580. M-CSF receptor antagonist GW2580 was dissolved in $0.5 \%$ hydroxyethyl cellulose/0.1\% Tween 80 .

Mice (2 weeks old) were given diethylnitrosamine (DEN) (20 $\mathrm{mg} / \mathrm{kg}$ ) intraperitoneally. Then, animals were divided into two groups. One group was treated immediately with GW2580 [80 $\mu \mathrm{g} /$ body weight (g)] or vehicle (control group) by gavage twice a day, and another group was started treatment at 4 weeks after DEN injection (Figure 1). Mice were sacrificed at 28 weeks after DEN injection and the number of tumors and tumor size were evaluated. The expression of CD31 as a marker of angiogenesis was evaluated by immunohistochemistry, and positive area was determined by image analysis. Distribution of F4/80 (as a marker of macrophages)positive and CD206 (as a marker of M2-type macrophages)-positive macrophages were analyzed by immunohistochemistry. In addition, distribution of CD68 (as a marker of macrophages)-positive and CD163 (as a marker of M2-type macrophages)-positive macrophages were analyzed by fluorescence double immunohistochemistry. Then, ratio of M2-type macrophage against all macrophages was assessed.

Kupffer cells were isolated from male $\mathrm{C} 3 \mathrm{H} / \mathrm{Hen}$ mice (10-12 weeks old), resuspended at a concentration of $5 \times 10^{6}$ cells $/ \mathrm{ml}$ in DMEM media in the presence or the absence of M-CSF $(100 \mathrm{ng} / \mathrm{ml})$ and/or GW2580 $(1 \mathrm{mg} / \mathrm{ml})$ and seeded at $1 \times 10^{4}$ cells $/ \mathrm{ml}$ per well. Cells were then incubated for the designated times at $37^{\circ} \mathrm{C}$ in $5 \%$ $\mathrm{CO}_{2}$, and supernatants were collected and stored at $-80^{\circ} \mathrm{C}$ for further analysis. The first group was only Kupffer cells, and the second group was Kupffer cells cultured in the presence of M-CSF, the third group was Kupffer cells cultured in the presence of M-CSF and GW2580, and the fourth group was Kupffer cell cultured in the presence of GW2580. Concentration of VEGF was determined at cell culture media using ELISA kits according to the manufacture's protocol (Ray Biotech, Peachtree Corners, GA, USA) at day 1, day 3, day 5.

The murine HCC cell line, MH134, which was originally induced by carbon tetrachloride in $\mathrm{C} 3 \mathrm{H} / \mathrm{He}$ mice, was generously provided by Chugai (Tokyo, Japan). MH134 cells were cultured with different concentrations of M-CSF (0, 1, 10 and $100 \mu \mathrm{g} /$ well) to assess direct effects of M-CSF against tumor growth in vitro, and the number of tumor cells was counted at day 1 , day 3 , and day 5 .

Isolation of Kupffer cells. Kupffer cells were isolated from mice as detailed elsewhere with minor modifications $(6,14)$. Briefly, mice were anesthetized with inhaled diethyl ether, the abdomen was opened, the portal vein was cannulated with a small length of polypropylene tube, ligated the inferior vena cava above the diaphragm, and the inferior vena cava was dissected. The liver was perfused in situ for $5 \mathrm{~min}$ with $\mathrm{Ca}^{2+} / \mathrm{Mg}^{2+}$-free liver perfusion medium 1 (LPM-1:8,000 mg/l NaCl, $400 \mathrm{mg} / 1 \mathrm{KCl}, 88.17 \mathrm{mg} / \mathrm{l}$ $\mathrm{NaH}_{2} \mathrm{PO}_{4}-2 \mathrm{H}_{2} \mathrm{O}, 120.45 \mathrm{mg} / \mathrm{l} \mathrm{Na} \mathrm{HPO}_{4}, 2380 \mathrm{mg} / \mathrm{l}$ HEPES, 350 $\mathrm{mg} / \mathrm{l} \mathrm{NaHCO}_{3}, 190 \mathrm{mg} / \mathrm{l}$ EDTA, $900 \mathrm{mg} / \mathrm{l}$ glucose, $6 \mathrm{mg} / 1$ Phenol red; $\mathrm{pH} 7.4,37^{\circ} \mathrm{C}$ ), and was then perfused with complete liver perfusion medium 2 (LPM-2: same as LPM-1 except without EDTA and glucose, but with $560 \mathrm{mg} / 1 \mathrm{CaCl}_{2}-2 \mathrm{H}_{2} \mathrm{O} ; \mathrm{pH} 7.4,37^{\circ} \mathrm{C}$ ) containing $0.06 \%$ collagenase type IV (Sigma, St. Louis, MO, USA) for additional $15 \mathrm{~min}$. After perfusion, the liver was removed, cut into small pieces, and homogenized. After passing through a $70 \mu \mathrm{m}$ nylon mesh to eliminate nondigested material, cells were washed twice with warm Gey's balanced salt solution (GBSS-B: $370 \mathrm{mg} / \mathrm{l}$ $\mathrm{KCl}, 210 \mathrm{mg} / 1 \mathrm{MgCl}_{2}-6 \mathrm{H}_{2} \mathrm{O}, 70 \mathrm{mg} / 1 \mathrm{MgSO}_{4}-7 \mathrm{H}_{2} \mathrm{O}, 150 \mathrm{mg} / 1$
$\mathrm{NaH}_{2} \mathrm{PO}_{4}-2 \mathrm{H}_{2} \mathrm{O}, 30 \mathrm{mg} / \mathrm{l} \mathrm{KH} \mathrm{PO}_{4}, 1,090 \mathrm{mg} / \mathrm{l}$ glucose, $227 \mathrm{mg} / \mathrm{l}$ $\mathrm{NaHCO}_{3}, 225 \mathrm{mg} / 1 \mathrm{CaCl}_{2}-2 \mathrm{H}_{2} \mathrm{O}, 6 \mathrm{mg} / \mathrm{l}$ phenol red, $8,000 \mathrm{mg} / \mathrm{l}$ $\mathrm{NaCl}, 100 \mathrm{U} / 1$ streptomycin, $105 \mathrm{U} / 1$ penicillin $\mathrm{G} ; \mathrm{pH}$ 7.4) and centrifuged over $16 \%(\mathrm{wt} / \mathrm{vol}) \mathrm{Nycodenz}^{\circledR}$ (Axis-Shields, Oslo, Norway) gradient for $20 \mathrm{~min}$ at $1,900 \times g$ at $4^{\circ} \mathrm{C}$. Kupffer cells were collected from under the interface, washed with GBSS-B and resuspended in D-MEM media (Invitrogen, Carlsbad, CA, USA) or PBS and used.

Immunohistochemistry for CD31, F4/80, and CD206. Briefly, formalin-fixed, paraffin-embedded tissue specimens were cut into 4$\mu \mathrm{m}$ sections. Each section was mounted on a silane-coated glass slide, deparaffinized, and incubated in antigen retrieval solution for $40 \mathrm{~min}$ at $95^{\circ} \mathrm{C}$ using Dako REAL Target Retrieval Solution (Dako, Carpinteria, CA, USA). Endogenous peroxidases were quenched by incubation at room temperature in $0.3 \% \mathrm{H}_{2} \mathrm{O}_{2}$, followed by rinsing with PBS. Endogenous biotin was quenched using Dako Biotin Blocking System (Dako). Sections were blocked using 5\% normal blocking serum for $20 \mathrm{~min}$. Rabbit polyclonal antibody to CD31 (1:50, Abcam, Cambridge, UK) was applied for $2 \mathrm{~h}$ at room temperature. Anti-F4/80 primary antibody (1:100, Serotec, Oxford, UK) was applied for $30 \mathrm{~min}$ at room temperature. CD206 (Anti-Mannose Receptor antibody) $\left(1: 1,000\right.$ Abcam) was applied overnight at $4^{\circ} \mathrm{C}$. Immunoperoxidase staining was completed using a Vectastain $\mathrm{ABC}$ elite kit (Vector Laboratories, Burlingame, CA, USA) and diaminobentizine (DAB) as a chromogen. The number of positive cells against each antibody was assessed under microscopy in five random (400x) fields for calculation of the proliferation index. Histological samples were evaluated by one of the authors and by an outside expert in rodent liver pathology. Quantitative analysis of the CD31 positive area was calculated from five different fields and indicated as a percentage of the total area of the field using Image $\mathbf{J}$ software.

Immunofluorescence double staining for CD68 and CD163. Briefly, formalin-fixed, paraffin-embedded tissue specimens were cut into 4- $\mu \mathrm{m}$ sections. Each section was mounted on a silane-coated glass slide, deparaffinized, and incubated in antigen retrieval solution for 20 min at $95^{\circ} \mathrm{C}$ using Dako REAL Target Retrieval Solution S1699 (Dako). Sections were blocked using 5\% normal blocking serum for 20 min. CD163/M130 polyclonal antibody (1:100; Bioss, MA, USA) or anti-CD68 antibody (FA-11) (1:100; Abcam) were applied for overnight at $4{ }^{\circ} \mathrm{C}$. Preabsorbed secondary antibodies Goat AntiRat IgG H\&L (Alexa Fluor 488) (Thermo Fisher Scientific K.K, Yokohama, Japan) and Goat Anti-rabbit IgG H\&L (Alexa Fluor 647) (Thermo Fisher Scientific K.K) were used at a 1/100 dilution for $2 \mathrm{~h}$ at room temperature. The number of positive cells against each antibody was assessed and evaluated in four random fields (200x) by BZ-X700 (Keyence, Osaka, Japan).

Statistical analysis. Data are expressed as mean \pm SEM. The Student's $t$-test was used for the determination of significance as appropriate. $p<0.05$ was considered significant.

\section{Results}

In animals administered with DEN, HCC was observed at 28 weeks after administration in the GW2580 non-treated group. On the other hand, tumor incidence was significantly blunted in both the early GW2580 administered and the late administered groups compared to the non-treated group 


\section{2 weeks after birth}

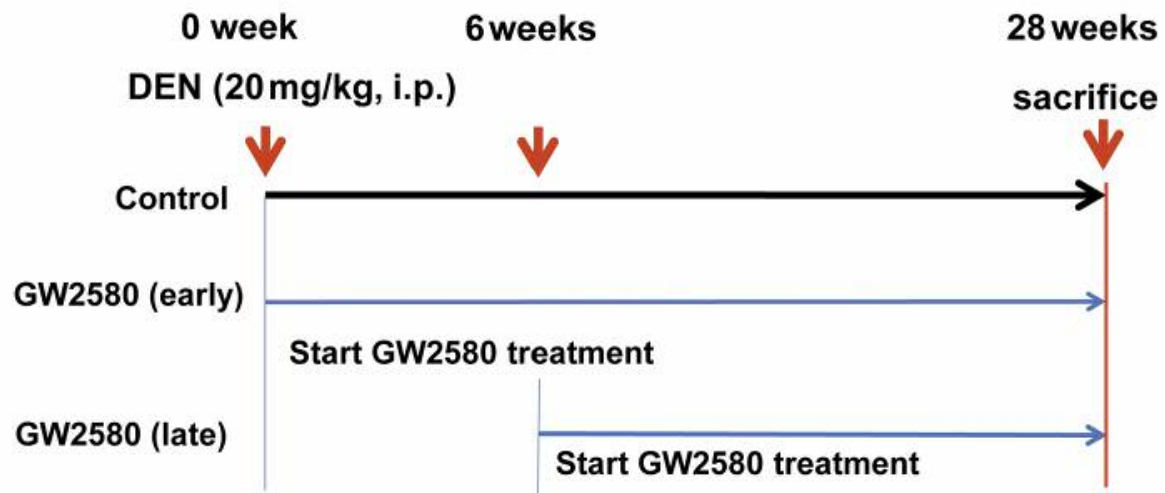

Figure 1. Experimental protocol. Control: Animals were orally administered HPC solution which does not contain GW2580. GW2580 early: animals were immediately administered GW2580 after DEN treatment. GW2580 late: animals started administration of GW2580 4 weeks after DEN treatment.

A

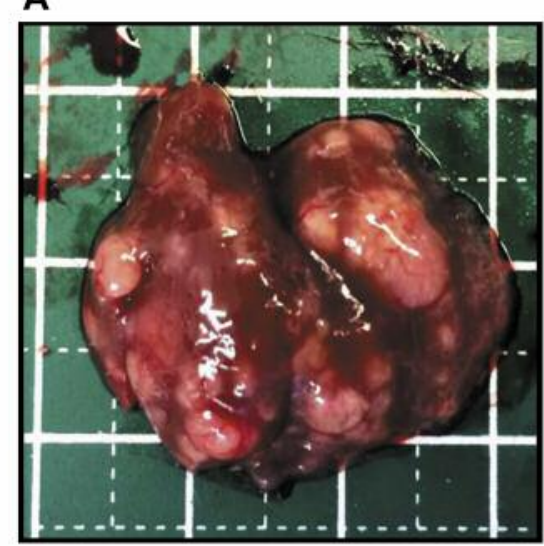

B
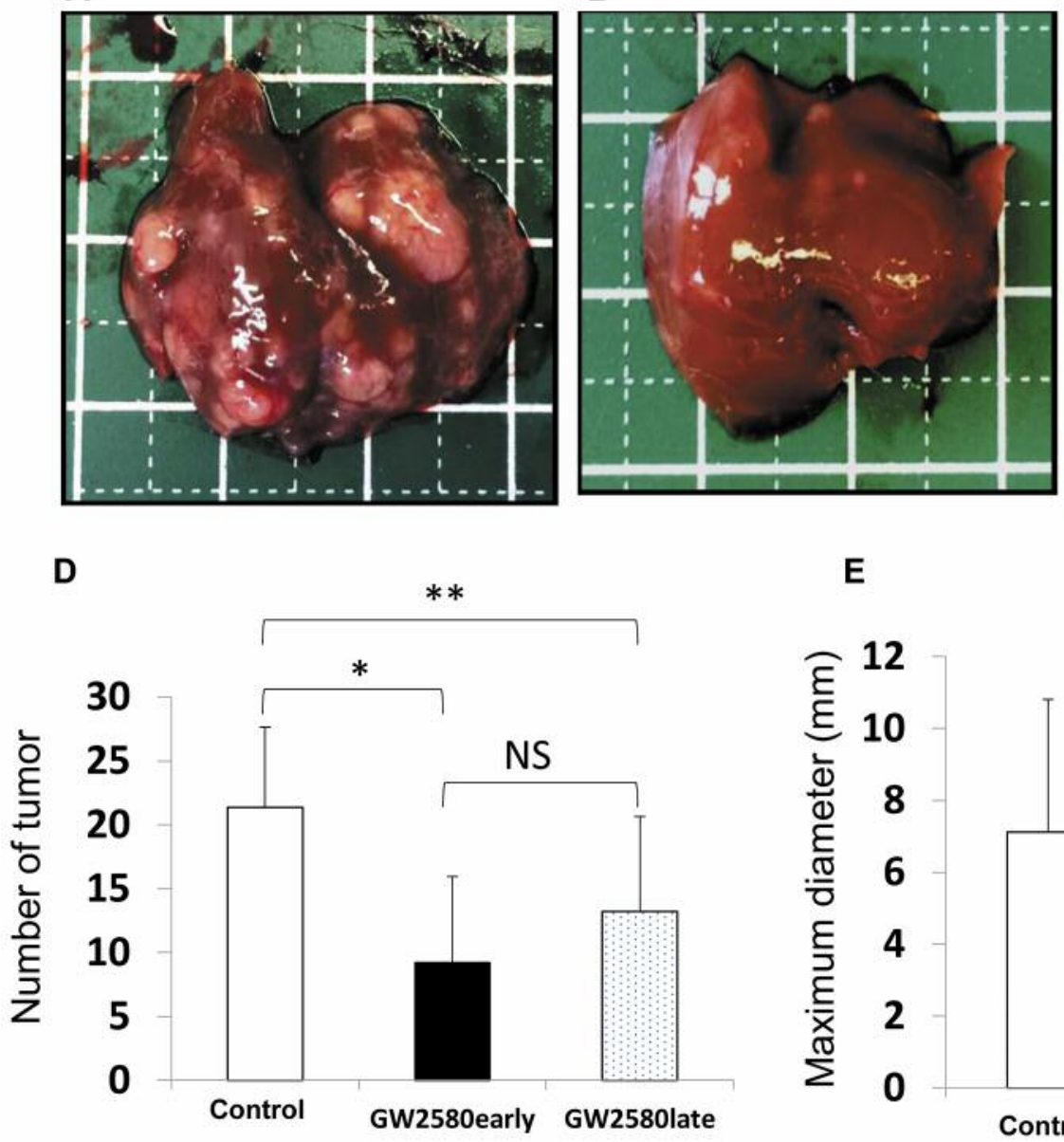

E

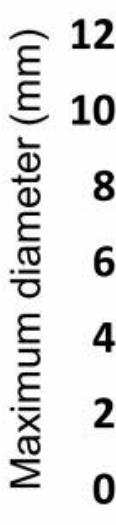

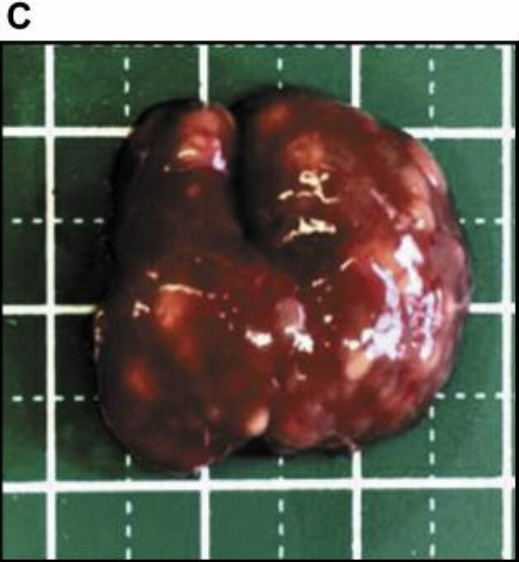

\#\#
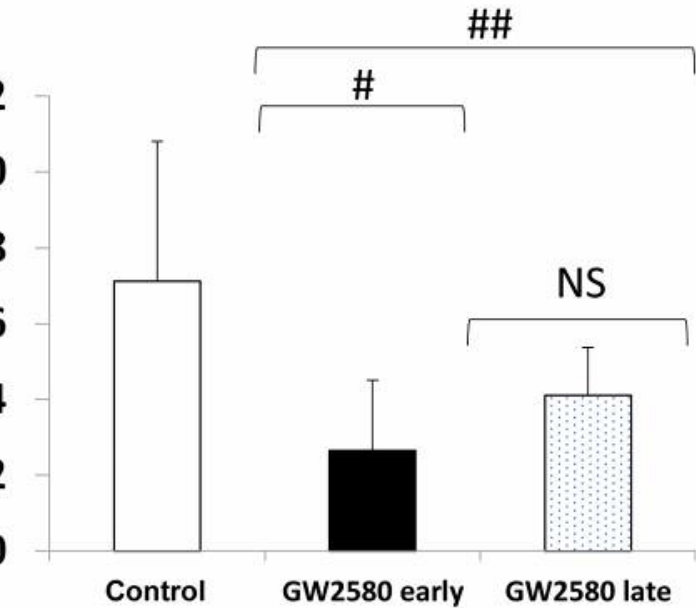

Figure 2. Effects of GW2580 in tumor growth. A; The control group, B: the GW2580 early-administered group and C: the GW2580 late administered group. The number of tumors $(D)$ and maximum tumor size (E) are shown. Data represent means \pm SEM. * and \#p $<0.01$ compared to the control mice by the unpaired Student's t-test. ** and ${ }^{\# \#} p<0.05$ compared to the control mice by the unpaired Student's $t$-test. 

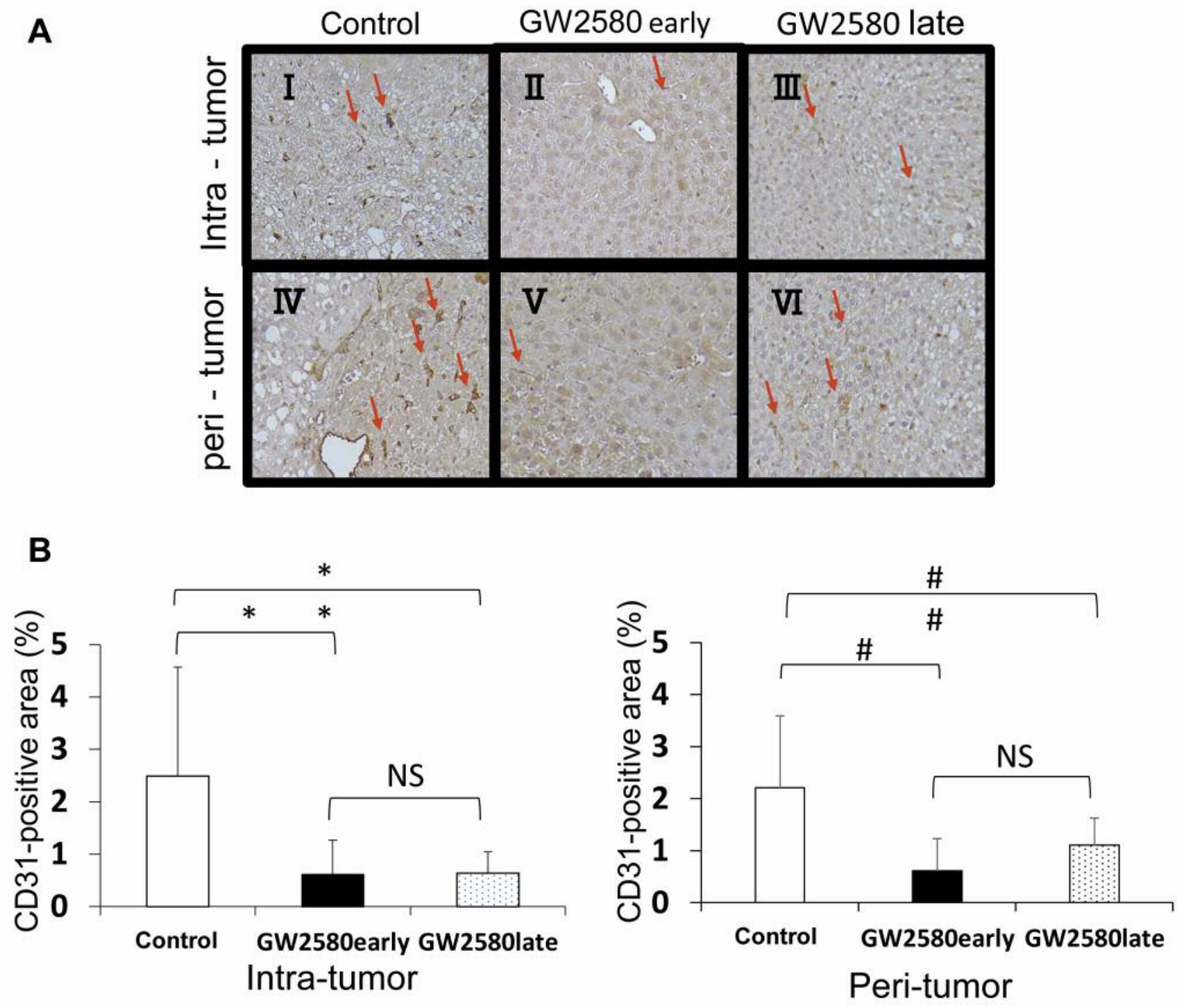

Figure 3. Immunohistochemistry for CD31 in the subcutaneous tissue. A: Representative photomicrographs are shown. B: Open bar, control mice; closed bar, GW2580 early-administered group; patterned bar, GW2580 late-administered group. Original magnification, $\times 400 . *, * *, \#$, and $\#$ \# $<0.01$ compared to the control mice by the unpaired Student's t-test.

(Figure 2A, B and C). Furthermore, the number and the maximum diameter of tumor were significantly blunted in both the early and the late GW2580 administered groups compared to the non-treated group (Figure 2D and E). There were no significant differences between the early group and the late administered group.

Analysis of angiogenesis in intratumor and peritumor tissues after the administration of DEN. To evaluate angiogenesis in the peritumor and intratumor tissues, immunohistochemical staining for CD31 was performed. The number of CD31-positive cells in the peritumor and intratumor tissues was significantly lower in both the early and late GW2580 administered groups than in the nontreated group. There were no significant differences between early administered group and late administered groups (Figure 3A and B).

Analysis of the phenotype of macrophages in intratumor and peritumor liver tissues after the administration of DEN. The ratio of M2-type macrophages (CD206)/M1-type macrophages (F4/80) in the peritumor tissues was also significantly lower in both the early and late GW2580 administrated groups than in the non-treated group (Figure 4A and B). 


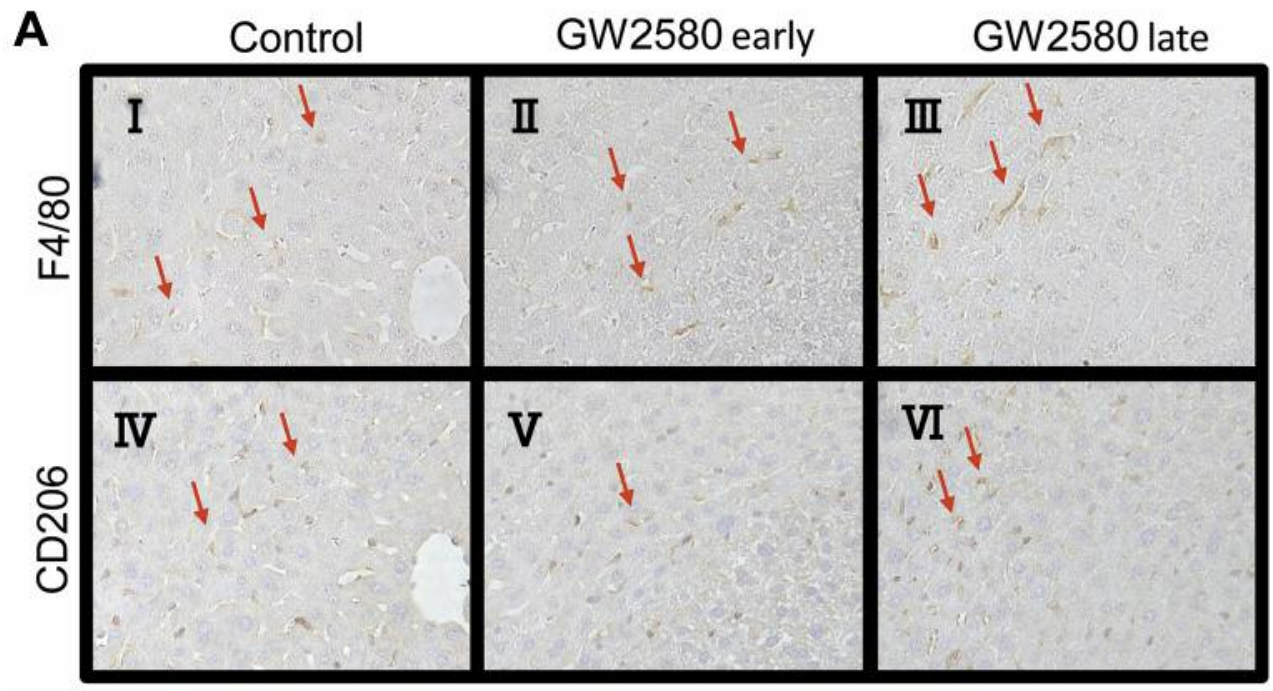

B

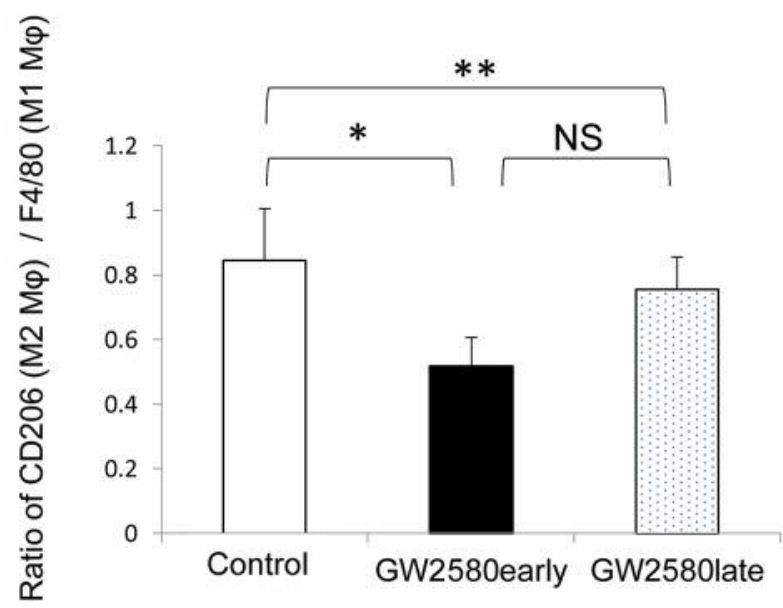

Figure 4. Immunohistochemistry for F4/80 and CD206 in the liver after the administration of DEN. A: Representative photomicrographs are shown. Original magnification, $\times 400$. F4/80-positive cells, M1-type macrophages and CD206-positive cells, M2-type macrophages. B: Open bar, control mice; closed bar, GW2580 early group and patterned bar, GW2580 late group. ${ }^{*} p<0.01$ compared to control mice by the unpaired Student's $t$-test. ** $p<0.05$ compared to the control mice by the unpaired Student's t-test.

Analysis of the population of hepatic macrophages after the administration of DEN. Double immunofluorescence staining indicated that the ratio of M2-type macrophages (CD163) / all macrophages (CD68) in the peritumor tissue was also significantly lower in both the early and the late GW2580 administered groups than in the non-treated group (Figure $5 \mathrm{~A}$ and $\mathrm{B}$ ). There were no significant differences between the early and the late administered groups.

Effects of GW2580 on the production of VEGF by M-CSFstimulated isolated Kupffer cells in vitro. Production of VEGF by isolated Kupffer cells increased in a time dependent manner (Figure 6A). The concentration of VEGF increased significantly in cells cultured in the presence of $\mathrm{M}$ -
CSF. This increase was significantly blunted in the presence of GW2580.

Effects of M-CSF on the proliferation of MH 134 cells in vitro. There were no significant differences in the number of MH134 among the groups studied, suggesting that proliferation of MH134 was not affected by treatment with $\mathrm{M}-\mathrm{CSF}$ in vitro (Figure 6B).

\section{Discussion}

Angiogenesis is strongly associated with oncogenesis and tumor growth $(12,15-17)$. A previous study from our laboratory showed that macrophages activated by M-CSF 


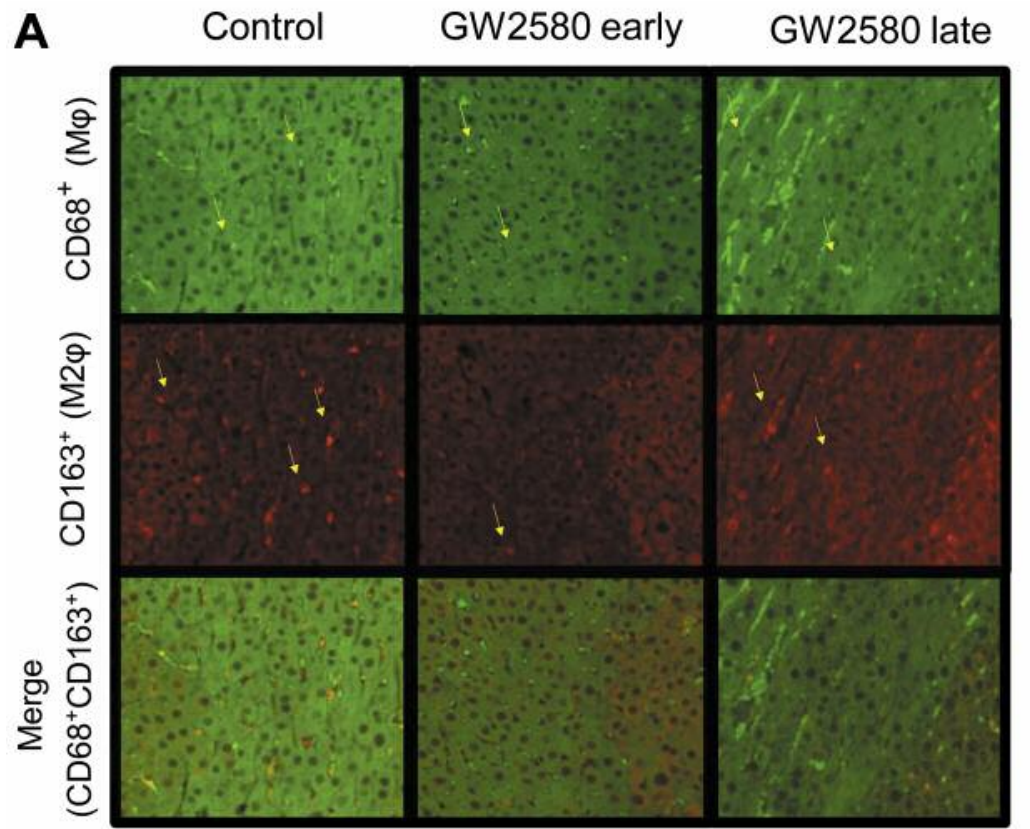

B

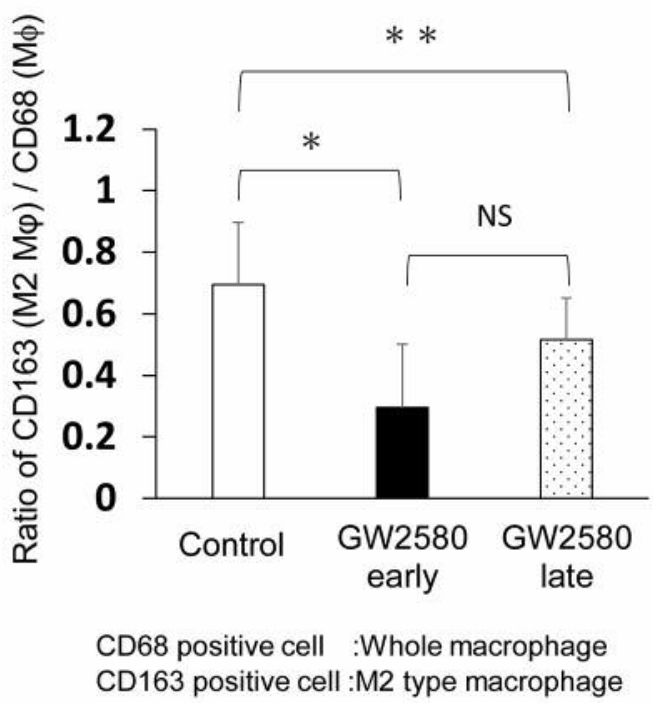

Figure 5. Double immunofluorescence staining for CD68 and CD163. A: Representative photomicrographs are shown. Original magnification, $\times 200$. CD68-positive cells (green); all macrophages and CD163-positive cells (red); M2-type macrophages. B: Open bar; control mice, closed bar; GW2580 early group, and patterned bar; GW2580 late group. ${ }^{*} p<0.01$ compared with the control mice by the unpaired Student's $t$-test. ${ }^{* *} p<0.05$ compared with the control mice by the unpaired Student's t-test.

A

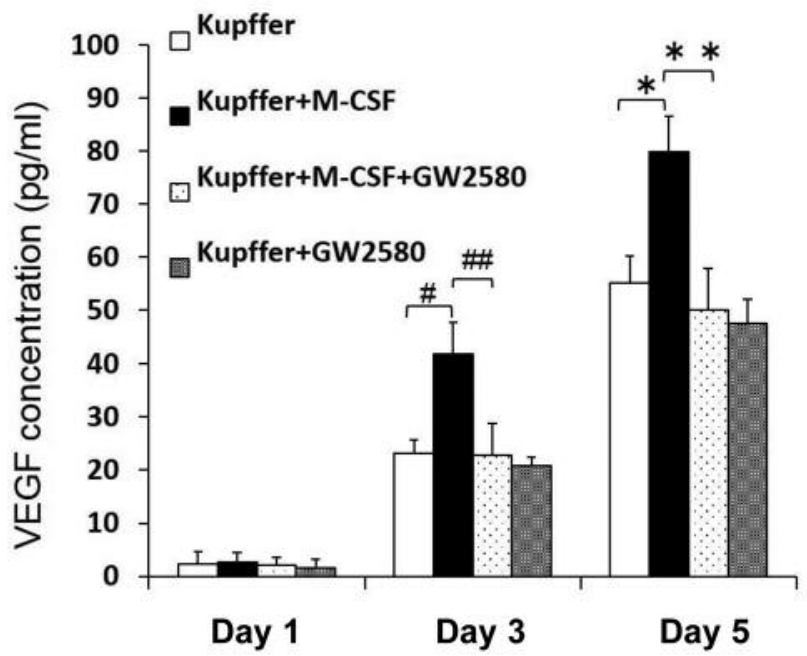

B

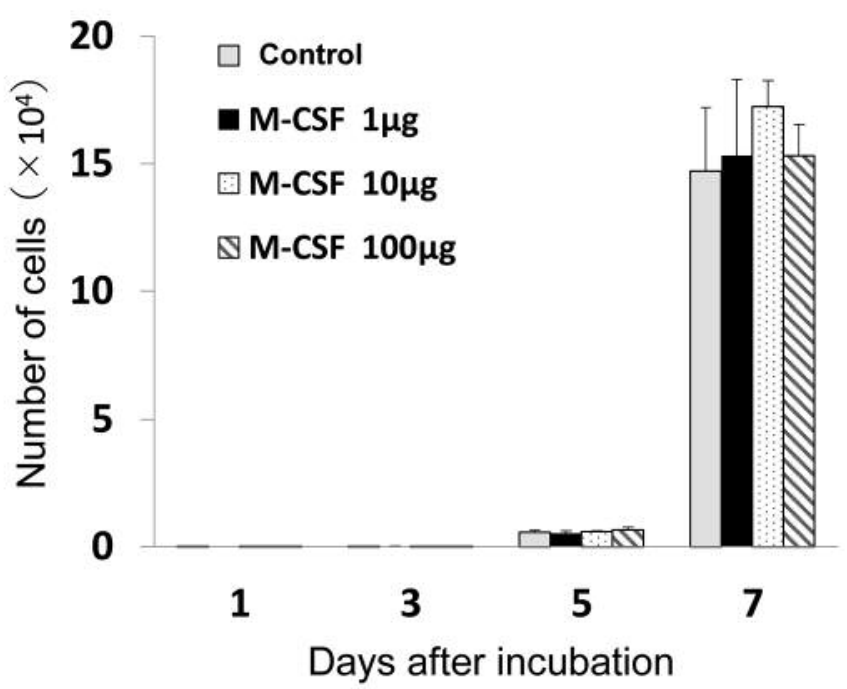

Figure 6. Effects of M-CSF and GW2580 on production of VEGF by isolated hepatic macrophages and proliferation of mouse HCC cell line in vitro. A) Production of VEGF by isolated Kupffer cells and B) proliferation of MH134 cells in vitro. Data are presented as the mean $\pm S E M .{ }^{\#} p<0.01$ compared with the control mice by the unpaired Student's $t$-test. ${ }^{\# \#} p<0.01$ compared to control mice by the unpaired Student's $t$-test. ${ }^{*} p<0.01$ compared with the control mice by the unpaired Student's $t$-test. ${ }^{*} p<0.01$ compared to the control mice by the unpaired Student's t-test. 
were involved in tumor initiation and progression $(18,19)$. M2-type macrophages include Kupffer cell expressing the MCSF receptor. It has been reported that M2-type macrophages activated by M-CSF induce neovascularization by increasing production of VEGF (6), which is an activator of angiogenesis. Importantly, VEGF production by isolated Kupffer cells was inhibited by GW2580 (Figure 6A). These results indicated that $\mathrm{M}-\mathrm{CSF}$ is involved in tumor progression by inducing production of VEGF by macrophages including Kupffer cells and monocytes.

In this study, occurrence of chemically induced HCC was significantly suppressed by treatment GW2580 in vivo, suggesting that the M-CSF receptor antagonists was effective in suppressing induction of hepatocarcinogenesis (Figure $2 \mathrm{E}$ ). The maximum diameter of the hepatic tumors was also significantly smaller in the GW2580 administered group (Figure 2D), suggesting that GW2580 also inhibited tumor progression. After DEN administration, oxidative stress derived from hepatic macrophages has been shown to be involved in carcinogenesis in the liver $(9,20,21)$. Thus, administration of GW2580 may lead to inhibition of activation of macrophages and reduction of oxidative stress.

GW2580 was not found to inhibit HCC cell proliferation, suggesting that it indirectly inhibits tumor growth (Figure 6B). It has previously been reported that Kupffer cells stimulated by M-CSF promote proliferation of vascular endothelial cells by producing VEGF $(6,13)$. In this study, VEGF production by isolated Kupffer cells was suppressed by GW2580 in vitro. After DEN administration, the ratio of M2-type/M1-type macrophages and the area of angiogenesis were reduced in both the early and the late GW2580 administered groups (Figure 3A and B). Thus, M-CSF most likely acts on macrophages to promote production of VEGF, leading to angiogenesis and tumor growth.

The mechanism of induction of HCC involves chronic inflammation caused by viral hepatitis, alcohol and nonalcoholic steatohepatitis, and chemicals, suggesting that prevention of inflammation could be effective in inhibiting occurrence of HCC (22). In these inflammatory conditions, activated Kupffer cells play a critical role. In this study, using a chemically-induced HCC model, oral medication by M-CSF receptor antagonist inhibited activation of Kupffer cells and occurrence or progression of tumor. Since oral medication is appropriate and easy for long-term therapy than intravenous administration, it may be possible to treat HCC using this compound long-term.

In conclusion, M-CSF and/or its receptor may be novel molecular targets for the therapy of HCC.

\section{Conflicts of Interest}

The Authors declare that they have no conflict of interest. No Authors disclosed any financial conflicts for this manuscript, and there were no personal relationships with other people or organizations that may have potentially and inappropriately influenced our work or conclusions.

\section{Authors' Contributions}

Yoshihiro Akazawa contributed to the data collection and writing of the paper; Hiroshi Kono contributed to the conception and design of the study; Michio Hara contributed to critical revision of the article; Shinji Furuya contributed to critical revision of the article; Yuuki Nakata contributed to the analysis and interpretation of the study; Hiroyuki Wakana contributed to data collection; Hisataka Fukushima contributed to data collection; Chao Sun contributed to the data collection and writing of the paper; Hideki Fujii contributed to the conception and design of this study, and obtained funding; Daisuke Ichikawa contributed to the conception and design of this study, and obtained funding.

\section{References}

1 Yoshida H, Hayashi S, Kunisada T, Ogawa M, Nishikawa S, Okamura H, Sudo T, Shultz LD and Nishikawa S: The murine mutation osteopetrosis is in the coding region of the macrophage colony stimulating factor gene. Nature 345(6274): 442-444, 1990. PMID: 2188141. DOI: $10.1038 / 345442 \mathrm{a} 0$

2 Zhu XD, Zhang JB, Zhuang PY, Zhu HG, Zhang W, Xiong YQ, Wu WZ, Wang L, Tang ZY and Sun HC: High expression of macrophage colony-stimulating factor in peritumoral liver tissue is associated with poor survival after curative resection of hepatocellular carcinoma. J Clin Oncol 26(16): 2707-2716, 2008. PMID: 18509183. DOI: 10.1200/JCO.2007.15.6521

3 Tsuchiya M, Kono H, Matsuda M, Fujii H and Rusyn I: Protective effect of juzen-taiho-to on hepatocarcinogenesis is mediated through the inhibition of kupffer cell-induced oxidative stress. Int J Cancer 123(11): 2503-2511, 2008. PMID: 18785209. DOI: $10.1002 / \mathrm{ijc} .23828$

4 Mantovani A, Sica A, Sozzani S, Allavena P, Vecchi A and Locati M: The chemokine system in diverse forms of macrophage activation and polarization. Trends Immunol 25(12): 677-686, 2004. PMID: 15530839. DOI: 10.1016/j.it.2004.09.015

5 Jia JB, Wang WQ, Sun HC, Zhu XD, Liu L, Zhuang PY, Zhang JB, Zhang W, Xu HX, Kong LQ, Lu L, Wu WZ, Wang L and Tang ZY: High expression of macrophage colony-stimulating factor-1 receptor in peritumoral liver tissue is associated with poor outcome in hepatocellular carcinoma after curative resection. Oncologist 15(7): 732-743, 2010. PMID: 20551429. DOI: $10.1634 /$ theoncologist.2009-0170

6 Almatroodi SA, McDonald CF, Darby IA and Pouniotis DS: Characterization of $\mathrm{m} 1 / \mathrm{m} 2$ tumour-associated macrophages (tams) and th1/th2 cytokine profiles in patients with nsclc. Cancer Microenviron 9(1): 1-11, 2016. PMID: 26319408. DOI: 10.1007/s 12307-015-0174-x

7 Mohamed MM, El-Ghonaimy EA, Nouh MA, Schneider RJ, Sloane BF and El-Shinawi M: Cytokines secreted by macrophages isolated from tumor microenvironment of inflammatory breast cancer patients possess chemotactic properties. Int J Biochem Cell Biol 46: 138-147, 2014. PMID: 24291763. DOI: 10.1016/j.biocel.2013.11.015

8 Liu C, Li Z, Wang L, Tong L, He N, Chen Y, Liu Y, Wu Z, Sun P, Xiang R, Ren G and Su W: Activating transcription factor 4 promotes angiogenesis of breast cancer through enhanced 
macrophage recruitment. Biomed Res Int 2015: 974615, 2015. PMID: 24291763. DOI: 10.1016/j.biocel.2013.11.015

9 Laoui D, Van OE, De BP, Van Ginderachter JA and Raes G: Functional relationship between tumor-associated macrophages and macrophage colony-stimulating factor as contributors to cancer progression. Front Immunol 5: 489, 2014. PMID: 25339957. DOI: 10.3389 /fimmu.2014.00489

10 Wang FQ, Chen G, Zhu JY, Zhang W, Ren JG, Liu H, Sun ZJ, Jia $J$ and Zhao YF: M2-polarised macrophages in infantile haemangiomas: Correlation with promoted angiogenesis. J Clin Pathol 66(12): 1058-1064, 2013. PMID: 23986554. DOI: 10.1136/jclinpath-2012-201286

11 Komohara Y, Ohnishi K, Kuratsu J and Takeya M: Possible involvement of the $\mathrm{m} 2$ anti-inflammatory macrophage phenotype in growth of human gliomas. J Pathol 216(1): 15-24, 2008. PMID: 18553315 . DOI: $10.1002 /$ path.2370

12 Folkman J: Proceedings: Tumor angiogenesis factor. Cancer Res 34(8): 2109-2113, 1974. PMID: 4842257.

13 Kono H, Fujii H, Furuya S, Hara M, Hirayama K, Akazawa Y, Nakata $\mathrm{Y}$, Tsuchiya $\mathrm{M}$, Hosomura $\mathrm{N}$ and Sun C: Macrophage colony-stimulating factor expressed in non-cancer tissues provides predictive powers for recurrence in hepatocellular carcinoma. World J Gastroenterol 22(39): 8779-8789, 2016. PMID: 27818593. DOI: 10.3748/wjg.v22.i39.8779

14 Wilson AJ, Saskowski J, Barham W, Khabele D and Yull F: Microenvironmental effects limit efficacy of thymoquinone treatment in a mouse model of ovarian cancer. Mol Cancer 14: 192, 2015. PMID: 26552746. DOI: 10.1186/s12943-015-0463-5

15 Folkman J: What is the evidence that tumors are angiogenesis dependent? J Natl Cancer Inst 82(1): 4-6, 1990. PMID: 1688381. DOI: $10.1093 /$ jnci/82.1.4

16 Ferrara $\mathrm{N}$ and vis-Smyth T: The biology of vascular endothelial growth factor. Endocr Rev 18(1): 4-25, 1997. PMID: 9034784 DOI: 10.1210/edrv.18.1.0287

17 Biswas SK, Sica A and Lewis CE: Plasticity of macrophage function during tumor progression: Regulation by distinct molecular mechanisms. J Immunol 180(4): 2011-2017, 2008. PMID: 18250403. DOI: 10.4049/jimmunol.180.4.2011
18 Lin EY, Nguyen AV, Russell RG and Pollard JW: Colonystimulating factor 1 promotes progression of mammary tumors to malignancy. J Exp Med 193(6): 727-740, 2001. PMID: 11257139. DOI: $10.1084 /$ jem.193.6.727

19 Lin EY, Li JF, Gnatovskiy L, Deng Y, Zhu L, Grzesik DA, Qian $\mathrm{H}$, Xue $\mathrm{XN}$ and Pollard JW: Macrophages regulate the angiogenic switch in a mouse model of breast cancer. Cancer Res 66(23): 11238-11246, 2006. PMID: 17114237. DOI: 10.1158/0008-5472.CAN-06-1278

20 Sun C, Kono H, Furuya S, Hara M, Hirayama K, Akazawa Y, Nakata $\mathrm{Y}$ and Fujii $\mathrm{H}$ : Interleukin-17a plays a pivotal role in chemically induced hepatocellular carcinoma in mice. Dig Dis Sci 61(2): 474-488, 2016. PMID: 26467699. DOI: 10.1007/ s10620-015-3888-1

$21 \mathrm{Li} \mathrm{X}$, Liu C, Ip BC, Hu KQ, Smith DE, Greenberg AS and Wang $\mathrm{XD}$ : Tumor progression locus 2 ablation suppressed hepatocellular carcinoma development by inhibiting hepatic inflammation and steatosis in mice. J Exp Clin Cancer Res 34: 138, 2015. PMID: 26560698. DOI: 10.1186/s13046-015-0254-2 22 Cervello M, Foderaa D, Florena AM, Soresi M, Tripodo C, D'Alessandro N and Montalto G: Correlation between expression of cyclooxygenase-2 and the presence of inflammatory cells in human primary hepatocellular carcinoma: Possible role in tumor promotion and angiogenesis. World J Gastroenterol 11(30): 4638-4643, 2005. PMID: 16094702. DOI: 10.3748/wjg.v11. i30.4638 